\title{
TITLE: The impact of new prehospital practitioners on ambulance transportation to Emergency Department: a systematic review and meta-analysis
}

Authors:

Hideo Tohira, ${ }^{\mathrm{a}, \mathrm{b}}$, Teresa A. Williams ${ }^{\mathrm{a}, \mathrm{b}, \mathrm{c}}$, Ian Jacobs ${ }^{\mathrm{a}, \mathrm{b}, \mathrm{c}}$, Alexandra Bremner ${ }^{\mathrm{d}}$, Judith Finn ${ }^{\mathrm{a}, \mathrm{b}, \mathrm{e}, \mathrm{e}}$

a Prehospital, Resuscitation and Emergency Care Research Unit, Faculty of Health Sciences, Curtin University, Bentley, Western Australia 6102 Australia

${ }^{b}$ Discipline of Emergency Medicine, School of Primary, Aboriginal and Rural Health Care, The University of Western Australia, Crawley, Western Australia 6009 Australia

c St John Ambulance, Western Australia, Belmont, Western Australia 6104 Australia

${ }^{\mathrm{d}}$ School of Population Health, The University of Western Australia, Crawley, Western Australia 6009 Australia

${ }^{\mathrm{e}}$ School of Public Health and Preventive Medicine, Monash University, Melbourne, Victoria 3000 Australia

\section{Abstract}

Study Objective: To conduct a systematic review and meta-analysis that examined the impact of new prehospital practitioners, including Emergency Care Practitioners (EmCPs), Paramedic Practitioners and Extended Care Paramedics (ECPs) on Emergency Department (ED) services.

Methods: We searched MEDLINE, Embase, CINAHL and AUSTHealth databases and handsearched the relevant journal and references in potentially relevant articles. To be included, studies were required to target one type of new prehospital practitioner and compare outcomes such as the frequencies of conveyances to ED, discharges at scene, subsequent ED attendances and/or appropriateness of care between new prehospital practitioners and conventional ambulance crews. Three investigators independently selected relevant studies. The risk of bias in individual studies was assessed using a check list developed and validated by Downs and Black. We conducted metaanalyses for comparisons which had an acceptable level of heterogeneity and reported pooled estimates of the odds ratio (OR) with 95\% confidence intervals (CIs).

Results: Thirteen relevant studies were identified from 16,584 citation reports. There were one experimental study, two quasi-experimental and 10 observational studies. EmCPs were most frequently studied. The majority of studies did not fully report potential confounding factors or adjust outcome measures for these. New prehospital practitioners were less likely to convey patients to ED and more likely to discharge patients at scene than conventional ambulance crews. Pooled ORs for conveyance to ED and discharge at scene by ECPs were 0.09 (95\% CI 0.04-0.18) and 10.5 (95\% CI 5.8-19), respectively. The evidence for subsequent ED attendance and appropriateness of care was equivocal. 
Conclusion: The new prehospital practitioner schemes reduced transport to EDs; however, appropriateness of the new prehospital practitioners' decision and safety of patients were not well supported by the reported studies. It remains uncertain whether NPP programs can alleviate ED crowding.

Keywords: emergency department; paramedics, extended role; emergency ambulance systems

\section{INTRODUCTION}

The Department of Health in the United Kingdom (UK) reported that ED presentations increased from 14 million in 2001-2 to 21 million in 2010-11.[1] When the demand for ED services exceeds available resources, ED crowding occurs, which can lead to delay in the delivery of time-sensitive care (e.g., thrombolysis for acute myocardial infarction).[2]

One strategy proposed to reduce demand for ED services is to decrease ambulance transportations to ED by providing care at the scene and/or referring a patient to an alternative health care service. New prehospital practitioners (NPPs), including Emergency Care Practitioners (EmCPs) and Paramedic Practitioners (PPs), were introduced in the United Kingdom (UK) in early 2000s to reduce the ED demand. $[3,4]$ In Canada, New Zealand and Australia, Extended Care Paramedics (ECPs), with a similar role to EmCPs, were introduced in late 2000s. The NPPs aim to provide pathways other than the default transport to ED for patients who suffer from minor illness or injury.

NPPs are similar to paramedics, but their role differs in that they have an expanded scope of clinical practice in patient assessment and treatment options. NPPs (EmCP, PP and ECP) are trained to manage minor illness and injury, e.g., perform simple suturing, order investigations such as x-rays and prescribe medications. They are also trained to decide whether a patient needs care at an ED or could be treated at home or in the community. Although there are some differences in the settings and prerequisite qualifications among NPPs, they are all able to provide care at the scene and discharge patients on site without referral to other clinicians.[3]

The impact of NPPs on emergency services has been reported in four published reviews,[5-8] in which the implementation of EmCP and PP programs reduced conveyances to ED. However, these reviews were not conducted in a systematic manner and did not include ECPs. To provide a more robust assessment of the strengths and limitations of the current evidence base and better inform policy decisions about the structure of prehospital emergency services, we have conducted a systematic review and meta-analysis of the impact of NPPs on patient transportation to ED. 


\section{METHODS}

This systematic review was registered with PROSPERO [CRD42012003142] before commencing the literature search.[9]

\section{Eligibility criteria}

To be included in our review, studies were required to meet four criteria: 1) the paper must report an original comparative study; 2) study participants must be those who sought an ambulance service; 3) the study must target one type of NPP; and 4) the study must report one or more of the following outcome measures: the number of patients discharged at scene, number of patients conveyed to ED, subsequent ED attendance and appropriateness of care provided/decisions made. We only included articles published in 2002 or later because NPP programs started after 2002. We did not set any language restriction for the literature search and intended to seek a translation service if required. Conference abstracts were included, but letters and commentaries were excluded.[10]

\section{Information source}

Databases searched for relevant studies were: Ovid MEDLINE (to 2012 October week 3), Ovid Embase (to 2012 week 43), EBSCO CINAHL (2002 to current) and Informit AUSTHealth (2002 to current). We also hand-searched emergency medicine journals (2002-2013) for relevant papers and journal reference lists.

\section{Search strategy}

We used the following text words and relevant subject headings in our search strategy: ("emergency care practitioner" or "paramedic practitioner" or "extended care paramedic") or [(“provider” or "practitioner” or "paramedic” or “new role” or “Emergency Medical Technician”) and (“ambulance” or "emergency medical service” or "prehospital” or "pre-hospital”)]. Subject headings were expanded if available. The detailed search strategies are available in Appendix 1.

\section{Study selection}

Three reviewers (HT, TW and JF) screened titles and abstracts of all retrieved studies for potentially relevant studies. Full text articles of these studies were reviewed by the same three reviewers. Disagreements in study eligibility were resolved by consensus. If multiple papers were generated from one study, we cited all papers but used the data from the most comprehensive paper and supplementary information from the other paper. We planned to contact corresponding authors if information was insufficient to determine eligibility for inclusion. 


\section{Data abstraction}

We created a data extraction form based on a Cochrane data extraction template.[11] We piloted and refined the form before the formal data extraction process began, then used it to record the following information about each study: author(s), study year, study location, study period, study design, participants, type of NPP, outcome measures and results. If a study reported information related to non-prehospital settings (e.g., ED), only data pertaining to a prehospital ambulance setting were collected. One reviewer (HT) extracted information and double-checked the accuracy and details of the extracted data.

\section{Assessment of risk of bias in individual studies}

We critically appraised relevant studies using a tool developed by Downs and Black.[12] The check list consisted of 27 questions: 25 with Yes/No answers scored 1 for 'Yes' and 0 for 'No'; one question about confounders scored 0 to 2; and another about sample size scored 0 to 5 . The maximum score was 32, with a higher score indicating lower risk of bias. The tool has been reported to perform well for both randomized and non-randomized studies.[12]

\section{Summary measures}

Outcomes were summarized using odds ratios (ORs) that compared the odds for NPPs to those for conventional ambulance crews. If there was not enough information to compute an OR, we presented other relevant information (e.g., percentages of events).

\section{Synthesis of results}

We used RevMan software version 5.1 to perform meta-analyses that employed the Mantel-Haenszel method in random effects models, which is the preferred approach when there is heterogeneity among studies.[13,14] We first performed analyses for each outcome measure including all types of NPP, and then conducted subgroup analyses for each type of NPP.

Heterogeneity was quantified using the $\mathrm{I}^{2}$ statistic.[15] An $\mathrm{I}^{2}$ statistic greater than $75 \%$ implies that there is high heterogeneity;[15] therefore, we decided not to report pooled results when the $\mathrm{I}^{2}$ statistic was greater than $75 \%$.

\section{Risk of bias across studies}

Risk of bias across studies was determined using the method proposed by Harbord et al.[16] We used the $5 \%$ significance level for this test. 


\section{RESULTS}

\section{Study selection}

We retrieved a total of 16,584 citations from the database searches. After excluding duplicate citations, 12,547 remained. We screened titles and abstracts and excluded 12,492 that clearly did not meet selection criteria. In addition to the 55 potentially relevant papers, we identified one paper from handsearching relevant journals and four papers from reference lists. Of the 60 papers eligible for full text review, 20 papers described the 13 studies that met our selection criteria and were included in this systematic review (Figure 1).

\section{Characteristics of included studies}

Characteristics of included studies are summarized in Table 1 . The majority of studies $(n=9)$ were conducted in the UK,[17-32] three studies in New Zealand,[33-35] and one in Canada.[36] EmCPs were most frequently studied.[17-20, 22-24, 28-32] The most frequently reported outcome measure was conveyance to ED,[18, 21-29, 33-36] followed by discharge at scene[18-22, 25-30, 33, 34, 36] and subsequent attendance at a health service.[18, 21, 22, 25-34] There were no individual patient randomized controlled trials, but there was one cluster randomized controlled trial, which generated four papers.[21, 25-27] 
Table 1 Characteristics of the included studies

\begin{tabular}{|c|c|c|c|c|c|c|c|}
\hline Study & Country & Study period & $\begin{array}{c}\text { No. of } \\
\text { patients }\end{array}$ & Type & Outcomes & Study design & $\begin{array}{l}\text { Follow up } \\
\text { period }\end{array}$ \\
\hline Cooper 2007[19, 20] & UK & $\begin{array}{l}\text { two 3-week periods in Feb } \\
2006 \text { and Apr/May } 2006\end{array}$ & 611 & $\begin{array}{l}\text { EmC } \\
P\end{array}$ & Discharge at scene & $\begin{array}{l}\text { Comparative } \\
\text { study }\end{array}$ & NA \\
\hline Halter 2006[24] & UK & Oct-Dec 2004 & 888 & $\begin{array}{l}\text { EmC } \\
P\end{array}$ & $\begin{array}{l}\text { Conveyance to ED } \\
\text { Patient satisfaction }\end{array}$ & $\begin{array}{l}\text { Comparative } \\
\text { study }\end{array}$ & NA \\
\hline Halter 2008[23] & UK & $\begin{array}{l}22 \text { Sep 2003-31 Jul } 2006 \\
\text { Jan 2007-Apr } 2007\end{array}$ & 152,796 & $\begin{array}{l}\text { EmC } \\
P\end{array}$ & $\begin{array}{l}\text { Conveyance to ED } \\
\text { Appropriateness of ECPs' } \\
\text { decision }\end{array}$ & $\begin{array}{l}\text { Comparative } \\
\text { study }\end{array}$ & NA \\
\hline Hoyle 2012[33] & $\begin{array}{l}\text { New } \\
\text { Zealand }\end{array}$ & 10 months from May 2009 & $1,000^{* 1}$ & ECP & Conveyance to ED & $\begin{array}{l}\text { Case series } \\
\text { Cohort study }\end{array}$ & NA \\
\hline
\end{tabular}




\begin{tabular}{|c|c|c|c|c|c|c|c|}
\hline Study & Country & Study period & $\begin{array}{c}\text { No. of } \\
\text { patients }\end{array}$ & Type & Outcomes & Study design & $\begin{array}{l}\text { Follow up } \\
\text { period }\end{array}$ \\
\hline $\begin{array}{l}\text { Mason 2008[21, 25- } \\
\text { 27] }\end{array}$ & $\mathrm{UK}$ & 1 Sep 2003 - 26 Sep 2004 & 3,018 & $\mathrm{PP}$ & $\begin{array}{l}\text { Discharge at scene } \\
\text { Conveyance to ED } \\
\text { Subsequent unplanned ED } \\
\text { attendance within } 7 \text { days } \\
\text { Patient satisfaction } \\
\text { Appropriateness of care }\end{array}$ & Cluster RCT & 7, 28 days \\
\hline Mason 2009[30-32] & UK & May 2006- August 2007 & 1,157 & $\begin{array}{l}\text { EmC } \\
P\end{array}$ & $\begin{array}{l}\text { Discharge at scene } \\
\text { Patient satisfaction } \\
\text { Subsequent health service use } \\
\text { Appropriateness of care }\end{array}$ & $\begin{array}{l}\text { Quasi- } \\
\text { experimental } \\
\text { study }\end{array}$ & 28 days \\
\hline Swain 2010[35] & $\begin{array}{l}\text { New } \\
\text { Zealand }\end{array}$ & ND (6 months) & 583 & ECP & Conveyance to ED & Case series & NA \\
\hline Swain 2012[34] & $\begin{array}{l}\text { New } \\
\text { Zealand }\end{array}$ & 8 Nov -13 Dec 2010 & 100 & ECP & $\begin{array}{l}\text { Discharge at scene } \\
\text { Conveyance to ED }\end{array}$ & $\begin{array}{l}\text { Comparative } \\
\text { study } \\
\text { Cohort study }\end{array}$ & NA \\
\hline
\end{tabular}




\section{Risk of bias in individual studies}

The median score using the Downs and Black's check list[12] was 21 (range 7-28). The majority of studies did not report important potential confounding factors or adjust outcome measures for these. Detailed results are available in Appendix 2.

\section{Results of individual studies}

Conveyance to ED

NPPs were 1.6 to 50 times less likely to convey patients to ED than conventional ambulance crews (Figure 2a).[18, 23, 24, 27, 28, 34, 36] In meta-analysis of the ECP subgroup, ECPs were 11.1 times less likely to convey patients to ED [Pooled OR (95\% CI) $=0.09(0.04-0.18), \mathrm{I}^{2}=40 \%$ ] (Figure 2b). We did not perform meta-analyses for conveyance to ED for other NPP types because of high heterogeneity. Three studies[22, 33, 35] reported the proportion of patients who were transported to ED by NPPs and conventional ambulance crews without sufficient information to compute ORs. One[22] of the three studies used two specific sub-cohorts (patients with breathlessness and patients who had fallen). All three studies reported that smaller proportions of patients were transported to ED by NPPs than conventional ambulance crews (40\% vs. $74 \%$;[33] 38\% vs. $63 \%$;[35] 36\% vs. $76 \%$ for the breathlessness cohort and $27 \%$ vs. $51 \%$ for the falls cohort[22]).

Discharge at scene

NPPs were 1.6 to 26 times more likely to discharge patients at the scene than conventional ambulance crews (Figure 3a).[18, 27, 28, 30, 34, 36] Meta-analysis of the ECP subgroup revealed that ECPs were 10.5 times more likely to discharge patients than conventional ambulance crews [Pooled OR (95\% $\mathrm{CI}$ ) 10.5 (5.8-19), $\left.\mathrm{I}^{2}=20 \%\right]$ (Figure 3b). Overall meta-analysis and other subgroup meta-analyses for this outcome were not performed because of high heterogeneity. Two studies[19, 22] reported proportions of patients who were discharged at scene without enough information to compute ORs. As in the previous section, one study[22] used the two sub-cohorts (breathlessness and falls cohorts). Both studies reported greater proportions of discharges at the scene for NPPs than conventional ambulance crews (48\% vs. 32\%;[19]64\% vs. $24 \%$ for the breathlessness cohort and $73 \%$ vs. $49 \%$ for the falls cohort[22]).

Subsequent ED attendance

There was no conclusive evidence about the impact of NPPs on subsequent ED attendance. Two studies (three comparisons) reported ORs for subsequent ED attendance (Figure 4).[26, 27, 30] Mason et al. reported ORs for two different follow-up periods: 7 and 28 days.[26, 27] One study reported a 26\% increase in ED attendance while two did not show a difference (Figure 4).[26] Cooper et al. 
reported that there was no subsequent ED attendance within 24 hours after the first contact with NPPs or conventional ambulance crews.[18] Mason et al. reported an $41 \%$ increase in subsequent health service contact after seen by EmCPs compared to conventional ambulance crews (unadjusted OR=1.41, 95\% CI not available).[28] There were variations in the follow-up period to study subsequent ED attendance. Three studies[26, 28, 30] followed-up patient outcome after contact by NPPs for 28 days, one study[27] followed-up patients for 7 days, and one[18] for 24 hours.

\section{Appropriateness of care/decision}

Four studies[17, 23, 27, 30] assessed the appropriateness of care provided or decisions made by NPPs with a 'review by experts', but each study used a different measure: a scale measure of appropriateness,[30] a dichotomous measure (Yes/No) of appropriateness,[23] avoidance of ED attendance for those discharged at the scene[17] and proportion of suboptimal care (Table 2).[27] As such, data synthesis was impossible. Coates et al. reported that the agreement between EmCPs and senior health care professionals on the avoidance of ED attendance was fair ( $\mathrm{k}=0.39)$.[37] Halter et al.[23] reported that EmCPs were significantly more likely to make appropriate decisions about patient disposition than conventional ambulance crews.[23] Mason et al. reported no significant difference in the appropriateness of care and the rate of suboptimal care between NPPs and conventional ambulance crews.[27, 30] 
Table 2 Summary of findings: Appropriateness of care/decision

\begin{tabular}{llcl} 
Studies & $\begin{array}{l}\text { Type of } \\
\text { provider }\end{array}$ & N & Appropriateness of decision/care \\
\hline Coates 2012[17] & EmCP & 172 & $\begin{array}{l}\text { Review by EmCPs and experts. For those discharged at scene, the reviewers } \\
\text { identified cases which were considered to have avoided an ED/hospital admission. } \\
\text { Agreement of decisions among reviewers: } \kappa=0.385 \text { (fair agreement) }\end{array}$
\end{tabular}

Halter 2008[23] EmCP 152,796 Review by experts. The experts judged if EmCPs decisions as to patient pathway were appropriate or not.

\% of 'appropriate decision': EmCP : non-EmCP=86.6\%:58.7\% (OR 4.55, 95\%CI: 2.61-7.92)

Mason 2009[30] EmCP 1,107 Review by experts. Overall care was rated on a numerical scale (1=unsatisfactory, 6= very best care) EmCP : non-EmCP=3.7 (95\%CI 3.4-4.1) : 4.2 (95\% CI 3.8-4.6)

Mason 2008[27] PP 3,018 Review by experts. The experts judged if there were suboptimal cares for the patients who made a subsequent unplanned ED attendance related to the initial episode. Proportion of patients without suboptimal cares: PP : non$\mathrm{PP}=73.5 \%: 72.9 \%$ (n.s.)

EmCP: Emergency Care Practitioner, PP: Paramedic Practitioner, ECP: Extended Care Paramedic, n.s.: not significant 
We examined publication bias across studies that reported discharge at scene and conveyance to ED. There was no significant publication bias detected among studies $(\mathrm{p}>0.1)$.

\section{DISCUSSION}

\section{Summary of evidence}

Our systematic review of the effect of NPPs on emergency services included 13 studies that met predetermined criteria. We identified one cluster randomized controlled trial which generated four papers[21, 25-27] and two quasi-experimental studies.[22, 30] The other 10 studies[17-20, 22-24, 28, 29, 31-36] were observational studies. Differences in baseline characteristics were common, and there was infrequent adjustment for potential confounders. Despite these limitations in study quality, we found that NPPs were more likely to discharge patients at the scene and less likely to convey patients to ED than conventional ambulance crews. The evidence for subsequent ED attendances and appropriateness of care/decision remains equivocal.

Although we could not perform meta-analyses for all outcome measures due to heterogeneity, there was evidence that the NPP program could reduce conveyances to ED and increase discharges at scene. All ORs for conveyance to ED and discharge at scene were statistically significant. Further, these favorable results for NPPs were consistent across the three types of NPP. The majority of studies have been conducted in the UK. More studies from countries where the NPP program has been implemented will supplement this evidence.

Patient safety has to be assured for the successful implementation of the NPP program. In this review, we considered two patient safety measures: appropriateness of care provided/decision made and subsequent ED attendance/hospital admission. The former is commonly used when assessing the appropriateness of decisions made by paramedics.[38-40] The latter is a relative measure which addresses the quality of the NPP's initial decision. For instance, if subsequent ED visits occur more often when patients are seen by NPPs than when seen by conventional paramedics, the initial NPP decision might not be adequate.We could not draw conclusions about patient safety using the measures. Subsequent ED attendances/hospital admissions were not able to be assessed due to variable inclusion criteria: for instance, Mason et al. included unplanned subsequent ED attendances only,[27] while two other studies[28, 30] identified both planned and unplanned subsequent ED attendances. The former criterion may be a better measure than the latter but the determination of what constitutes a planned versus unplanned ED attendance is somewhat subjective. Follow-up periods to determine patient outcomes were also different across the studies: 24 hours, 7 days and 28 days. Mason et al. noted that most serious adverse results would have occurred within 7 days after the initial contact.[27] If subsequent unplanned ED attendance occurred a 'prolonged' period after the 
initial episode (and 'prolonged' was not defined), such a late re-presentation may be more related to chronic etiology rather than acute illness.

There was considerable variation in the methods used to review appropriateness of care and decisions made by NPPs. Consistent use of the same method may facilitate evidence generation.

\section{Limitations}

This review has several limitations at study and review level. Observational studies were included; therefore, differences in potential confounders between NPP group and conventional ambulance crew group are likely to exist, and the majority of studies did not adjust for potential confounders, e.g., age and/or patient clinical presentation. If characteristics of groups are different, their study results may be misleading and cannot be generalized.

We could not conduct meta-analyses for all outcome measures due to heterogeneity among studies, even though we performed subgroup analyses, which is a technique to reduce heterogeneity by grouping similar studies.[41] The small number of studies did not facilitate further subgroup analysis to examine the reason for the heterogeneity. A potential source of heterogeneity was the variability in case-mix between the NPP and conventional ambulance crews.[23, 33] For example, patients with cardiac etiology were more likely to be conveyed to ED, while those with minor cuts were more likely to be discharged at scene. The distribution of clinical presentations in each group should be reported.

Other sources of heterogeneity include the inconsistency of education programme and the mode of deployment across regions studied. The duration of education programme ranges from one month[35] to two years.[19, 42] Master level NPPs might be more likely to make appropriate decisions than those who completed one month training programmes. The mode of deployment of NPPs might also affect patient disposition. Patients seen by paramedics who call NPPs are unlikely to be conveyed to ED because the paramedics have already decided the patient could be treated by NPPs.

Only two studies[27, 28] reported patient destinations other than ED or discharge at scene and compared them between NPPs and conventional ambulance crews. This information might be important for those who educate NPPs and policy makers. Both studies reported NPPs were more likely to refer patients to other health services, e.g., community social service. This implies that NPPs may require skills to determine whether a given patient may be more appropriately treated at another health service. Educational programs for NPPs may need to include information about community health services. Further, if the NPP program is implemented, the number of attendances at other health services may increase, and policy makers may need to plan to improve the accessibility and availability of these health services. 
Although we conducted an extensive literature search, we could only identify 13 studies and all were conducted in the U.K., Canada, and New Zealand. In the U.S., Emergency Medical TechnicianParamedics can perform similar or even advanced skills compared with new prehospital health care providers. However, in the 200 largest US cities, discharge at the scene without medical oversight was sanctioned in only five cities.[43]

\section{Future directions}

Future research should focus on the safety of patients attended by NPPs. Six studies[17, 18, 23, 27, 28, 30] assessed patient safety by using subsequent ED attendance after being seen by NPPs and/or appropriateness of care/decision made by NPPs. However, we could not draw generalized evidence regarding patient safety because the methods employed varied between studies, Policy makers may be reluctant to embrace the concept of NPP without evidence of patient safety. Studies that use the consistent and/or standardised methods are required.

Future research should also focus on the impact of the NPP schemes on ED crowding. Although the NPP schemes have the potential to reduce the demand for ED services, it is still uncertain whether the NPP schemes can mitigate ED crowding. Several studies reported that the diversion of nonurgent patients had little effect on ED crowding.[44-46] The NPP schemes are similar to this divertnonurgent-patients strategy in terms of the reduction of input to EDs. Thus, the NPP schemes may not alleviate ED crowding.

\section{CONCLUSION}

The implementation of NPP schemes reduced patient conveyance to ED and may reduce unnecessary transportation of patients by providing care at the place where a patient resides. However, rigorous evidence about the appropriateness of decisions made by NPPs and the safety of patients is lacking. This information is crucial for policy makers and other stakeholders to inform decision-making and ensure patient safety. Standardisation of methods to evaluate the appropriateness of decisions is needed.

\section{DECLARATION OF INTEREST}

Ian Jacobs is the Clinical Services Director at St John Ambulance Western Australia (SJA-WA), Judith Finn receives partial salary support from SJA-WA for her role as Adjunct Professorial Research Fellow and Teresa Williams is a non-compensated Adjunct Senior Research Fellow at SJAWA. 


\section{FUNDING}

This review was funded by the Targeted Research Fund, Western Australia Department of Health.

\section{REFERENCES}

1. Department of Health. Archive - Accident and Emergency Attendances. 21 November 2011. Available from http://webarchive.nationalarchives.gov.uk/20130107105354/http://www.dh.gov.uk/en/Publica tionsandstatistics/Statistics/Performancedataandstatistics/AccidentandEmergency/DH_08797 3.

2. Collis J. Adverse effects of overcrowding on patient experience and care. Emergency Nurse 2010;18:34-39.

3. Modernisation Agency/Department of Health. The Emergency Care Practitioner Report. London, 2004.

4. Mason S, Wardrope J, Perrin J. Developing a community paramedic practitioner intermediate care support scheme for older people with minor conditions. Emerg Med J 2003;20:196-8.

5. Snooks HA, Dale J, Hartley-Sharpe C, et al. On-scene alternatives for emergency ambulance crews attending patients who do not need to travel to the accident and emergency department: a review of the literature. Emerg Med J 2004;21:212-5.

6. Cooper S, Jr., Grant J. New and emerging roles in out of hospital emergency care: a review of the international literature. International emergency nursing 2009;17:90-8.

7. Coates D. ECPs: avoiding emergency department attendance or hospital admission? Journal of Paramedic Practice 2010;2:158.

8. Hoskins R. Evaluating new roles within emergency care: a literature review. International emergency nursing 2011;19:125-40.

9. Centre for Reviews and Dissemination. PROSPERO: International prospective register of systematic reviews. Available from http://www.crd.york.ac.uk/PROSPERO/.

10. Hopewell S, McDonald S, Clarke M, et al. Grey literature in meta-analyses of randomized trials of health care interventions. Cochrane Database of Systematic Reviews 2007.

11. Data collection form for non-randomized studies. In: Higgins J, Green S, eds. Cochrane Handbook for Systematic Reviews of Interventions version 5.0.0 (electric version), 2008.

12. Downs SH, Black N. The feasibility of creating a checklist for the assessment of the methodological quality both of randomised and non-randomised studies of health care interventions. Journal of Epidemiology and Community Health 1998;52:377-84.

13. Mantel N, Haenszel W. Statistical aspects of the analysis of data from retrospective studies of disease. Journal of National Cancer Research 1959;22:719-48.

14. Review Manager (RevMan) [program]. 5.1 version. Copenhagen, 2011. 
15. Higgins JPT, Thompson SG, Deeks JJ, et al. Measuring inconsistency in meta-analyses. BMJ 2003;327:557-60.

16. Harbord RM, Egger M, Sterne JAC. A modified test for small-study effects in meta-analyses of controlled trials with binary endpoints. Stat. Med. 2006;25:3443-57.

17. Coates D, Rawstorne S, Benger J. Can emergency care practitioners differentiate between an avoided emergency department attendance and an avoided admission? Emerg Med $J$ 2012;29:838-41.

18. Cooper S, Barrett B, Black S, et al. The emerging role of the emergency care practitioner. Emerg Med J 2004;21:614-8.

19. Cooper S, O'Carroll J, Jenkin A, et al. Collaborative practices in unscheduled emergency care: role and impact of the emergency care practitioner--quantitative findings. Emerg Med $J$ 2007;24:630-3.

20. Cooper S, O'Carroll J, Jenkin A, et al. Emergency care practitioners (ECP): practice and performance in the UK West country--a case study. International emergency nursing 2008;16:180-4.

21. Dixon S, Mason S, Knowles E, et al. Is it cost effective to introduce paramedic practitioners for older people to the ambulance service? Results of a cluster randomised controlled trial. Emerg Med J 2009;26:446-51.

22. Gray JT, Walker A. Avoiding admissions from the ambulance service: a review of elderly patients with falls and patients with breathing difficulties seen by emergency care practitioners in South Yorkshire. Emerg Med J 2008;25:168-71.

23. Halter M, Ellison G. Evaluation of the emergency care practitioner role in London: a study of the processes and outcomes of clinical decision making. London: The Faculty of Health and Social Care Sciences, University of London, 2008.

24. Halter M, Marlow T, Tye C, et al. Patients' experiences of care provided by emergency care practitioners and traditional ambulance practitioners: A survey from the London Ambulance Service. Emerg Med J 2006;23:865-66.

25. Knowles E, Mason S, Colwell B. An initiative to provide emergency healthcare for older people in the community: the impact on carers. Emerg Med J 2011;28:316-19.

26. Mason S, Knowles E, Colwell B, et al. Effectiveness of paramedic practitioners in attending 999 calls from elderly people in the community: cluster randomised controlled trial. BMJ 2007;335:919.

27. Mason S, Knowles E, Freeman J, et al. Safety of paramedics with extended skills. Acad Emerg Med 2008;15:607-12.

28. Mason S, O'Keeffe C, Coleman P, et al. A national evaluation of the clinical and cost effectiveness of Emergency Care Practitioners, Phase two, Final Report. In: Medical Care Research Unit SoHaRR, University of Sheffield, ed., 2005.

29. Mason S, O'Keeffe C, Coleman P, et al. Effectiveness of emergency care practitioners working within existing emergency service models of care. Emerg Med J 2007;24:239-43. 
30. Mason S, O'Keeffe C, Coleman P, et al. A Multi-Centre Community Intervention Trial to Evaluate the Clinical and Cost Effectiveness of Emergency Care Practitioners. Report for the National Insitute for Health Research Service Delivery and Organisation programme: Health Services Research, School of Health and Related Research, University of Sheffield, 2009.

31. Mason S, O'Keeffe C, Knowles E, et al. A pragmatic quasi-experimental multi-site community intervention trial evaluating the impact of Emergency Care Practitioners in different UK health settings on patient pathways (NEECaP Trial). Emerg Med J 2012;29:4753.

32. O'Hara R, O'Keeffe C, Mason S, et al. Quality and safety of care provided by emergency care practitioners. Emerg Med J 2012;29:327-32.

33. Hoyle S, Swain AH, Fake P, et al. Introduction of an extended care paramedic model in New Zealand. Emerg Med Australas 2012;24:652-6.

34. Swain AH, Al-Salami M, Hoyle SR, et al. Patient satisfaction and outcome using emergency care practitioners in New Zealand. Emerg Med Australas 2012;24:175-80.

35. Swain AH, Hoyle SR, Long AW. The changing face of prehospital care in New Zealand: the role of extended care paramedics. N Z Med J 2010;123:11-4.

36. Jensen JL, Travers AH, Bardua DJ, et al. Transport outcomes and dispatch determinants in a novel expanded scope paramedic-long-term care program. Canadian Journal of Emergency Medicine 2012;14:S13.

37. Byrt T. How Good Is That Agreement? Epidemiology 1996;7:561.

38. Gratton MC, Ellison SR, Hunt J, et al. Prospective detemination of medical necessity for ambulance transport by paramedics. Prehospital Emergency Care 2003;7:466-69.

39. Hauswald M. Can paramedics safely decide which patients do not need ambulance transport or emergency department care? Prehospital Emergency Care 2002;6:383-83.

40. Price TG, Hooker EA, Neubauer J. Prehospital Provider Prediction of Emergency Department Disposition. Prehospital Emergency Care 2005;9:322-25.

41. Sutton AJ. Methods for meta-analysis in medical research. West Sussex, UK: John Wiley \& Sons, 2000.

42. Adams A, Wright K, Cooke M. Evaluation of the NHS Changing Workforce Programme's Emergency Care Practitioners Pilot Study in Warwickshire: Centre for Primary Health Care Studies, Division of Health in the Community, Medical School, University of Warwick, 2005.

43. Knapp BJ, Kerns BL, Riley I, et al. EMS-Initiated Refusal of Transport: The Current State of Affairs. J. Emerg. Med. 2009;36:157-61.

44. Sprivulis P, Grainger S, Nagree Y. Ambulance diversion is not associated with low acuity patients attending Perth metropolitan emergency departments. Emerg Med Australas 2005;17:11-5.

45. Afilalo J, Marinovich A, Afilalo M, et al. Nonurgent emergency department patient characteristics and barriers to primary care. Acad Emerg Med 2004;11:1302-10. 
46. Howard MS, Davis BA, Anderson C, et al. Patients' perspective on choosing the emergency department for nonurgent medical care: a qualitative study exploring one reason for overcrowding. J Emerg Nurs 2005;31:429-35. 


\section{Figure legends}

Figure 1 Flow diagram of study selection process

Figure 2 Forest plots for conveyance to ED

ED: Emergency Department, EmCP: Emergency Care Paramedic, PP: Prehospital Practitioner, ECP:

Extended Care Paramedic

Figure 3 Forest plots for discharge at scene

ED: Emergency Department, EmCP: Emergency Care Paramedic, PP: Prehospital Practitioner, ECP:

Extended Care Paramedic

Figure 4 Forest plot for subsequent ED attendance

*: 7-day follow-up; **: 28-day follow-up 


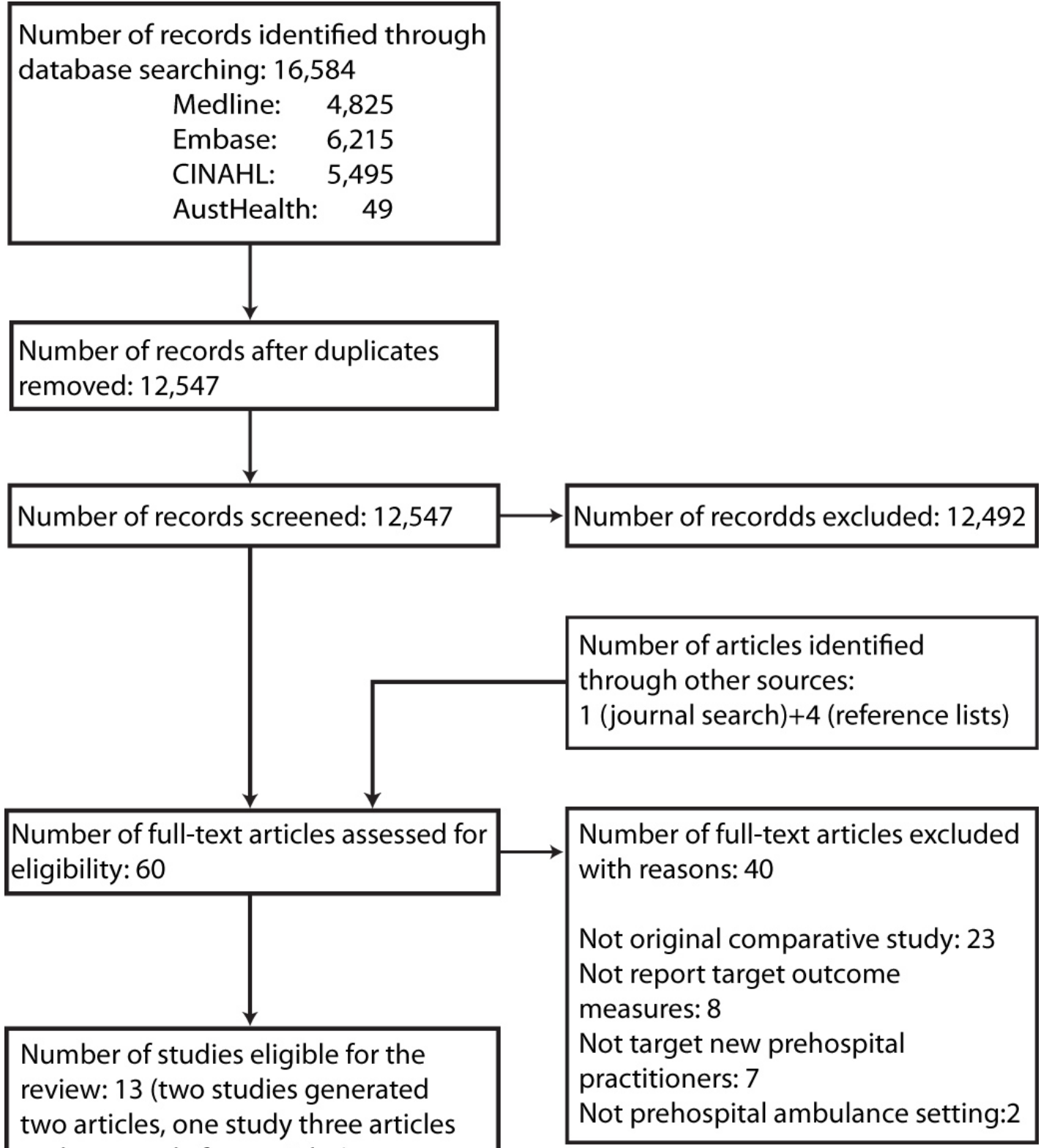

and one study four articles) 


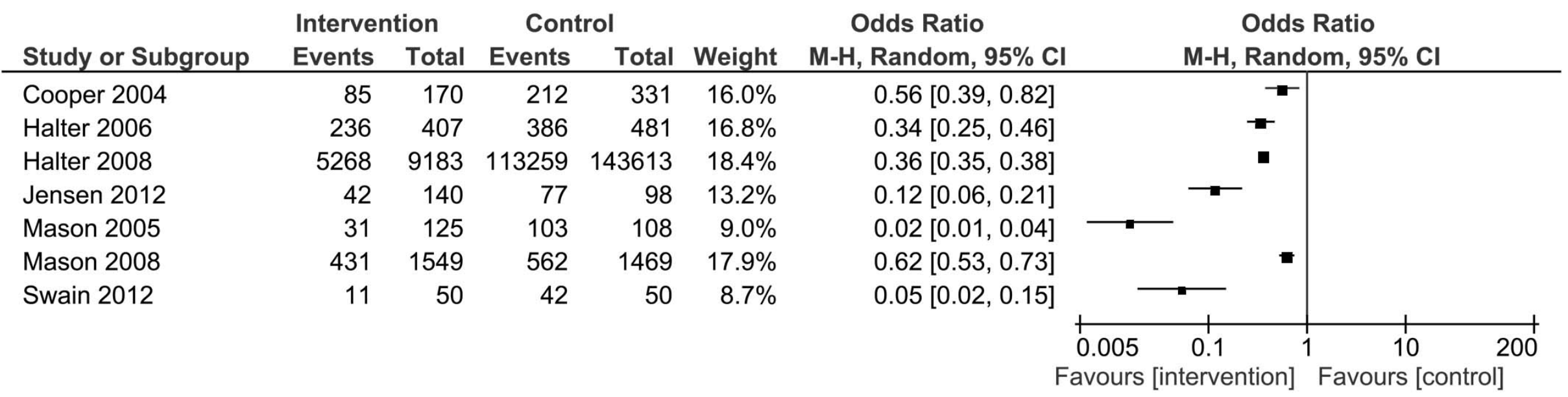

Figure 2a Forest plot for conveyance to ED by EmCP, PP and ECP

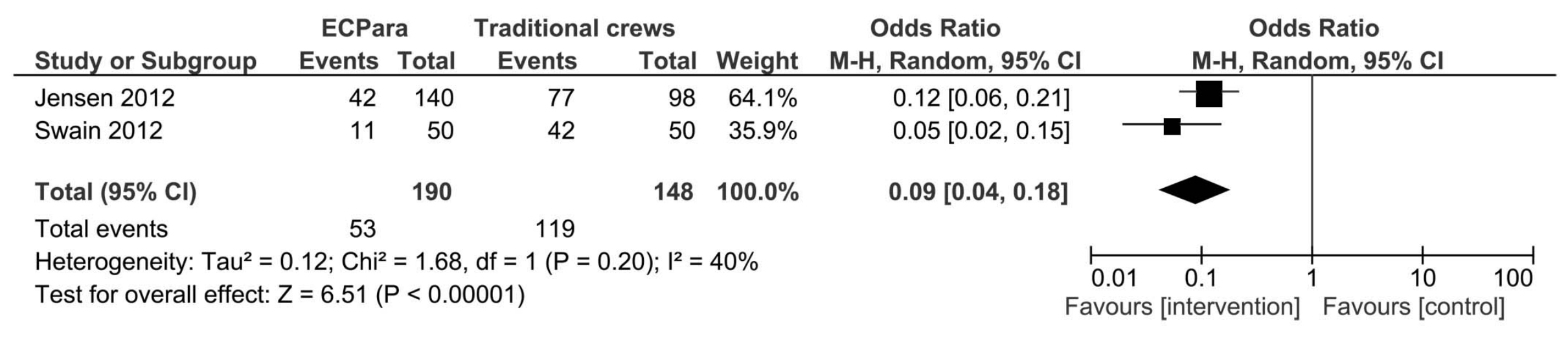

Figure $2 b$ Pooled ORs for conveyance to ED by ECP 


\begin{tabular}{|c|c|c|c|c|c|c|c|c|c|c|}
\hline \multirow[b]{2}{*}{ Study or Subgroup } & \multicolumn{2}{|c|}{ Intervention } & \multicolumn{2}{|c|}{ Control } & \multirow[b]{2}{*}{ Weight } & Odds Ratio & \multirow{2}{*}{\multicolumn{3}{|c|}{$\begin{array}{c}\text { Odds Ratio } \\
\text { M-H, Random, } 95 \% \mathrm{Cl}\end{array}$}} & \\
\hline & Events & Total & Events & Total & & M-H, Random, $95 \% \mathrm{Cl}$ & & & & \\
\hline Cooper 2004 & 48 & 170 & 59 & 331 & $17.4 \%$ & $1.81[1.17,2.81]$ & & & -- & \\
\hline Jensen 2012 & 98 & 140 & 21 & 98 & $16.8 \%$ & $8.56[4.68,15.63]$ & & & & \\
\hline Mason 2005 & 70 & 125 & 5 & 108 & $15.2 \%$ & $26.22[9.99,68.78]$ & & & & \\
\hline Mason 2008 & 1118 & 1549 & 907 & 1469 & $18.0 \%$ & $1.61[1.38,1.87]$ & & & $=$ & \\
\hline Mason 2009 & 257 & 593 & 34 & 514 & $17.5 \%$ & $10.80[7.36,15.85]$ & & & $\rightarrow-$ & \\
\hline Swain 2012 & 38 & 50 & 8 & 50 & $15.1 \%$ & $16.63[6.14,45.03]$ & & & & \\
\hline & & & & & & & $\begin{array}{l}0.01 \\
\text { Fav }\end{array}$ & $\begin{array}{l}0.1 \\
\text { ours [control] }\end{array}$ & $\begin{array}{r}10 \\
1\end{array}$ & $\begin{array}{c}100 \\
\text { ventionl }\end{array}$ \\
\hline
\end{tabular}

3a Forest plot for discharge at scene by EmCP. PP and ECP

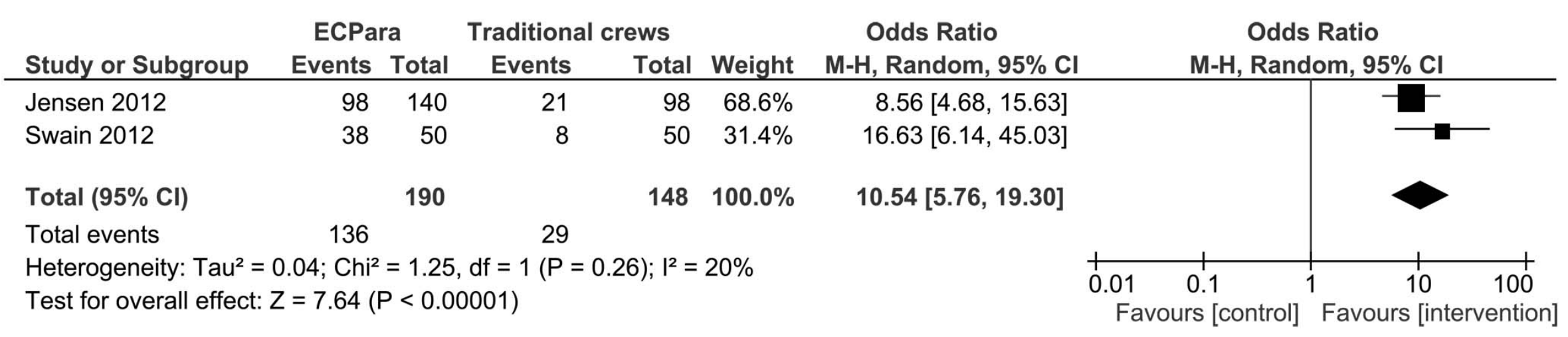

Figure 3b Pooled ORs for discharge at scene by ECP 
Intervention Control Odds Ratio Odds Ratio

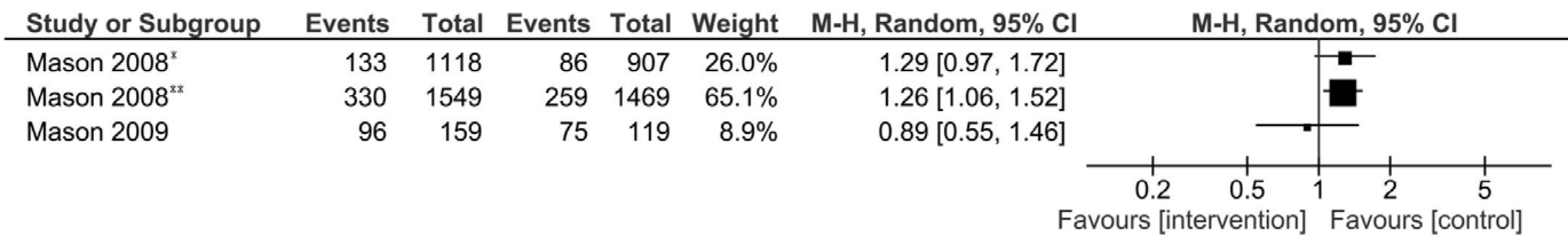

Figure 4 